\title{
Listu-guruinaren enbriogenesia eta seinalizazio-bideak
}

\author{
(Salivary gland embriogenesis and signaling pathways) \\ Patricia Garcia-Gallastegi ${ }^{1 *}$, Olatz Crende Arruabarrena ${ }^{2}$ \\ ${ }^{1}$ Zelulen Biologia eta Histologia Saila, Medikuntza eta Erizaintza Fakultatea \\ (UPV/EHU) \\ ${ }^{2}$ Zelulen Biologia eta Histologia Saila, Farmazia Fakultatea \\ (UPV/EHU)
}

LABURPENA: Ugaztunen listu-guruina egitura epitelial bat da, oso adarkatuta garatzen dena eta listua ekoizteko eta jariatzeko diseinatuta dagoena. Gizakietan hiru listu-guruin nagusi daude. Hala ere, barailapeko listu-guruina da aztertuena. Berrikuspen honetan, saguaren barailapeko listu-guruinaren enbrioi-garapeneko garaiak azaltzen dira. Aldi berean, garapeneko prozesu honek gidatzen dituen oinarrizko seinalizazio-bideak eta mekanismoak laburbiltzen dira: FGF, Shh, Notch, Wnt, Eda, ECMak eta nerbio-sistema. Garapenean zehar agertzen diren mekanismoak hobeto ulertzea funtsezkoa da kaltetutako guruinaren birsorkuntza-terapia eraginkorrak diseinatzeko.

HITZ GAKOAK: Listu-guruinaren garapena, Barailapeko listu-guruina, Seinalizazio-bideak.

ABSTRACT: Mammalian salivary gland is an epithelial structure that is highly branched during development and is designed to produce and secrete saliva in the body. There are three main types of salivary glands; however, the most commonly studied is submandibular salivary gland. This review describes the different stages of the mouse embryo salivary gland development. At the same time, it summarizes the basic signaling pathways and mechanisms that guide this development process; FGF, Shh, Notch, Wnt, Eda, ECMs and the nervous system. Understanding the mechanisms that operate during development is essential for the design of effective therapies for affected gland and regeneration.

KEYWORDS: Salivary gland development, submandibular salivary gland, Signaling pathways.

\footnotetext{
* Harremanetan jartzeko / Corresponding author: Patricia Garcia-Gallastegi, Zelulen Biologia eta Histologia Saila, Medikuntza eta Erizaintza Fakultatea, UPV/EHU. Sarriena Auzoa, z/n (48940 Leioa-Bizkaia). - patricia.garcia@ehu.eus - https:// orcid.org/0000-0002-5140-3390.

Nola aipatu / How to cite: Garcia-Gallastegi, Patricia; Crende Arruabarrena, Olatz (2019). «Listu-guruinaren enbriogenesia eta seinalizazio-bideak»; Ekaia, 36, 2019, 163-174. (https://doi.org/10.1387/ekaia.20733).

Jasoa: 2 maiatza, 2019; Onartua: 15 uztaila, 2019.

ISSN 0214-9001 - eISSN 2444-3255 / (c) 2019 UPV/EHU

(c) (1) (2) Obra hau Creative Commons Atribución 4.0 Internacional-en

BY NC SA lizentziapean dago
} 


\section{SARRERA}

Listu-guruinak aho-barrunbearekin loturiko organoak dira. Horien funtzioa listua ekoiztea da. Listua hitz egiteko, dastatzeko, murtxikatzeko, irensteko eta digeritzeko ezinbestekoa da. Listuak lubrikazioan, aho-immunitatean eta homeostasian parte hartzen du. Aldi berean, aho-barrunbeko zauriak osatzen ere parte hartzen du, listuan hazkuntza-faktoreak eta peptido biologikoak kantitate txikitan disolbaturik baitaude.

Gizakien eta karraskarien listu-aparatua hiru guruin nagusiz osatuta dago: barailapeko listu-guruina (submandibular salivary gland edo SMG), listu gehien jariatzen duena, mihipeko listu-guruina (sublingual edo SLG) eta parotida (parotid edo PG). Guztiak aho-barrunbearekin konektaturik daude jariapen-hodi baten bitartez. Gainera, ahoko eta mingaineko mukosa listu-guruin txikiz beterik dago (600-1.000), eta horien hodiak motzak eta adarkatuak dira [1].

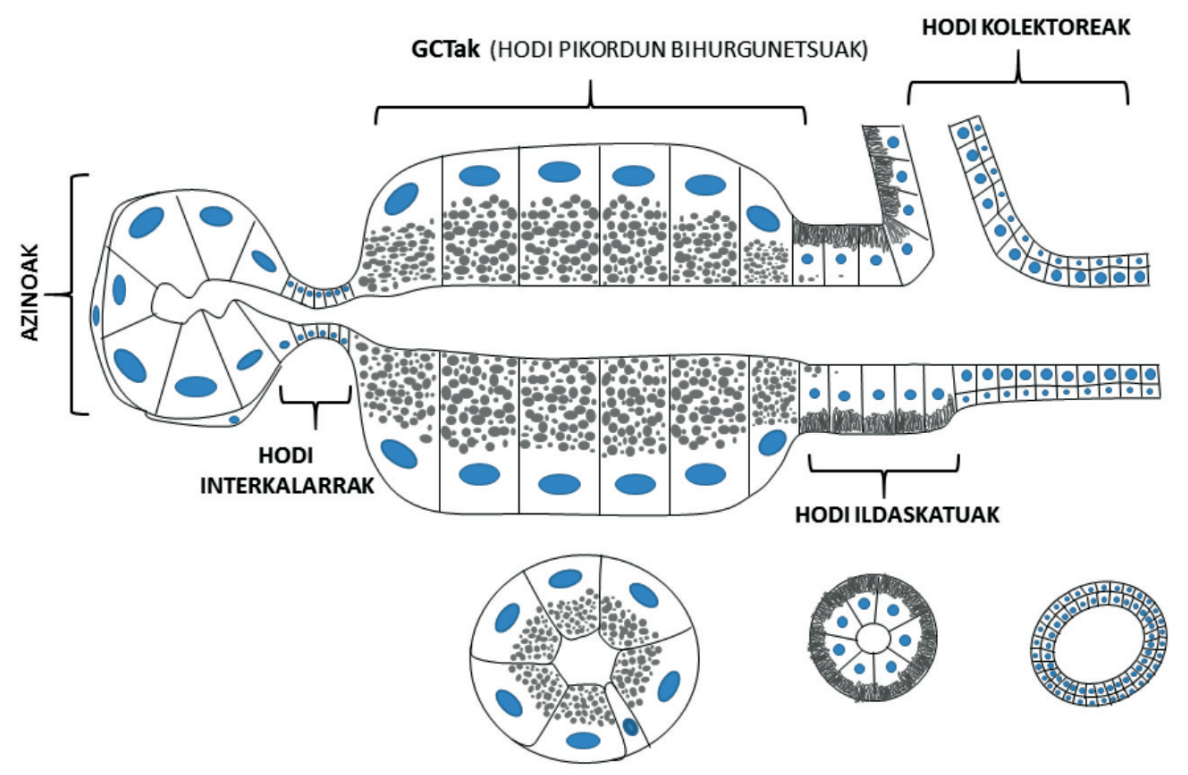

1. irudia. Saguaren SMGren egitura eskematikoa. Alde batetik, azino mukosoak eta azino serosoak zelula mioepitelialez* inguraturik daude. Listuaren bidea azinoetatik diametro txikiko hodi interkalarretara doa. Ondoren, GCT (granular convoluted tubules) hodietara, zeinek, handiagoak izateaz gainera, ohiko pikorrak dituzten. Listua GCTetatik pasatu ostean hodi ildaskatuetara garraiatzen da, zeinek oin-aldeko mintz-tolesturak dituzten. Azkenik, hodi kolektoreetara garraiatzen da. Hodi horrek argirik handiena du, eta epitelio sasigeruzatuaz osaturik dago (www. pathologyoutlines.com orrialdetik moldatua). 
Listu-guruinaren enbriogenesia eta seinalizazio-bideak

Listu-guruina (1. irudia) azino- eta jariapen-hodiz osaturik dago. Azinoak serosoak edo mukosoak izan daitezke, jariakinaren arabera (urtsua edo likatsua den, hurrenez hurren). Muki-zelulek muzinak jariatzen dituzte, karbohidrato kateak dituzten glikoproteina luzeak. Oro har, muzinek karga negatiboa dute, eta listuaren likatasuna mantentzen dute. Azino serosoetako zelulek proteinak jariatzen dituzte (adibidez, amilasa). Zenbait azino seromukosoak dira, muzina zein proteinak jariatzen dituztelako. Listua azinoetan ekoizten da, baina, hodietan zehar garraiatzen denean, konposizioa aldatu egiten da. Listua azinoetako hodi interkalarretatik hodi ildaskatuetara garraiatzen da. Gizakietan ez bezala, karraskarien SMGetan beste hodi bat agertzen da, interkalarren eta ildaskatuen artean: hodi pikordun bihurgunetsuak (GCTak). Hodi horiek dimorfismo sexualaren menpe daude, arretan ugariagoak izaten baitira [2].

Izar-itxurako zelula mioepitelialek azino eta hodi interkalarrak inguratzen dituzte. Zelula horien uzkurdura nerbio-sistema sinpatikoaren eta parasinpatikoaren estimuluen menpe dago, eta listua azinoetatik kanporatzea eta hodietatik garraiatzea eragiten du.
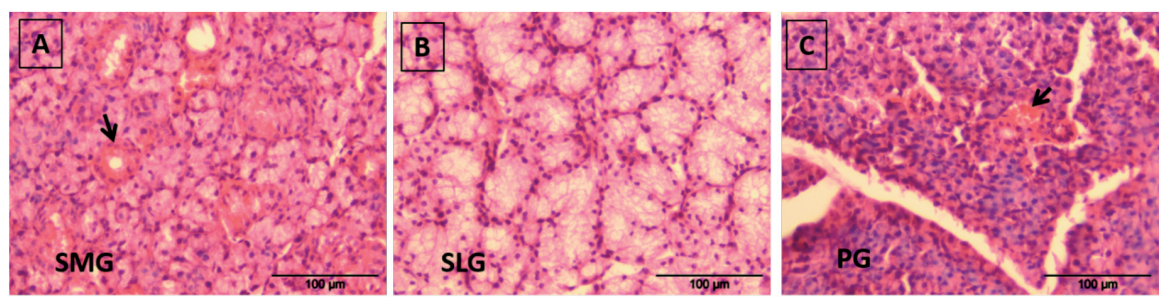

2. irudia. Listu-guruinaren histologia. (A) Barailapeko listu-guruina edo SMG, H/Erekin tindatua, mistoa da (geziak GCTa seinalatzen du) (B) Mihipeko listu-guruina edo SLG, H/Erekin tindatua, mukosoa da. (C) Listu-guruin parotida edo PG, H/Erekin tindatua (geziak hodi ildaskatuak seinalatzen ditu).

Saguen listu-guruin parotida (2C irudia) serosoa da nagusiki. Hori dela eta, hematoxilina-eosina $(\mathrm{H} / \mathrm{E})$ tindaketarekin basofiloagoa agertzen da. Aldiz, SLGren (2B irudia) edukia mukosoa da. Beraz, hematoxilinarekin ahulago tindatzen da. SMG (2A irudia) listu-guruin mistoa da, zelula serosoz eta mukosoz osatua.

Sagu ar eta emeen hiru listu-guruin handienen jardueren artean ezberdintasunak daude. Adibidez, aminotransferasaren aktibitatea antzekoa da ar eta emeen parotidan eta mihipeko listu-guruinetan. Barailapeko listu-guruinetan, berriz, aktibitatea 10 aldiz altuagoa da arretan emeetan baino [3]. Nahiz eta helduetan listu-guruinek antzekotasun morfologikoa izan, haien funtzionamenduan ezberdintasunak daude. 
Maiz zenbait gaitzen, gaixotasunen edo buruko eta lepoko minbizien kontrako erradioterapiek listu-guruinaren funtzioa kaltetzen dute. Asaldura horiek xerostomia («aho lehorraren sindromea») izeneko disfuntzioa eragiten dute, pazienteentzat deserosoa dena eta haien bizi-kalitatean eragin negatiboa duena $[4,5]$. Beraz, listu-guruinen garapena ezagutzea ezinbestekoa da birsorkuntzarako estrategiak diseinatzeko, eta horrek interes handia pizten du. Horretarako, beharrezkoa da listu-guruinaren zelula amen biologia ezagutzea [6], inerbazioa [7] eta listu-guruinaren morfogenesia zuzentzen dituzten seinalizazio-bideak [8-12] sakonki ikertzea.

\section{LISTU-GURUINAREN GARAPENA}

Hiru listu-guruin bikote nagusiak aho-epiteliotik sortzen dira. Aho-ektodermoaren eta sabel gaineko endodermoaren artean agertzen dira. Hala ere, listu-guruinak sortzen diren toki zehatza zein den ez dago oso argi, baina uste da estomodeoa eta jatorrizko faringearen barrunbea banatzen diren puntutik hurbil egongo daitekeela [13].

Hasiera batean iradoki zen listu-guruin parotidak ektodermoan zuela jatorria; barailapekoak eta mihipekoak, berriz, endodermoan [14]. Baina, listu-guruinaren zelula aitzindariak hepatoktemizatutako gibelean txertaturik, pankreako zelulak eta hepatozitoak desberdintzen zirela ikusi zenean [15], jatorri endodermikoaren hipotesia indartu zen. Ordea, nahiz eta listu-guruinen zelula aitzindariak mikroinguru egoki batean halako zelulatan desberdintzeko ahalmena izan, horrek ez du jatorriaren hipotesia guztiz frogatzen.

Genetikako leinu-jarraipeneko teknikari esker eta leinu-ezpezifikoak diren Cre gidariak erabiliz, Cre-errekonbinasak DNAn delekzioak eragiten ditu, gene espezifikoetan sekuentziak gehituz. Sekuentzia horien produktuak koloretsuak dira, eta hala gidariekin listu-guruineko zenbait zelularen jatorria ezagutzea lortu da. Wnt1-cre leinu-jarraipenarekin [16] mesenkimak eta nerbioak gandor neuraletik eratorriak direla ikusi da. Azken urteotan Sox17-2A-iCre/R26R saguak erabiliz egindako leinu-jarraipeneko esperimentuetan, non endodermoko zelulak markatuak dauden, ikusi da hiru listu-guruin nagusien epitelioek ez dutela jatorria endodermoan, ektodermoko jatorriaren hipotesia indartuz [17].

Gainera, animalia-ereduetan eta giza mutazioek eragindako displasia ektodermikoetan (garapeneko sindrome bat, non jatorri ektodermikoko ehunak nagusiki kaltetuak agertzen diren), ikusi da listu-guruin nagusiak ektodermoan dauden zelula multipotenteetatik abiatuta sortzen direla. Dena den, datu horiek guztiak ez dira erabakigarriak, listu-guruinaren ektodermo-jatorria berretsi behar baita [18]. 
Listu-guruinaren enbriogenesia eta seinalizazio-bideak

Enbrioian, lehenengo barailapeko listu-guruina garatzen da, jarraian mihipekoa, eta azkenik parotida. Ugaztunen listu-guruinak enbrioi-garapenean sortzen dira, adarkatze morfogenesia deituriko prozesuaren bitartez. Prozesu hori ezinbestekoa da beste organo batzuen garapenerako ere; esaterako, birika, giltzurruna eta ugatz-guruina garatzeko [1].

Listu-guruinaren garapenaren hasiera, zelulen proliferazio eta barneratze koordinatu batekin hasten da. Biribil-itxurako epitelioa, kimu deiturikoa, hazi egiten da inguratzen duen mesenkima bultzatuz doan heinean. Aldi berean, zelulak mugitzen, hiltzen eta elkarrekin erlazionatzen dira. Epitelioko zelulak mesenkimako zelulekin, neuronekin eta endotelioko zelulekin harremanetan jartzen dira. Ondoren desberdintzapena gertatzen da, eta zelula mota ezberdinak sortzen dira.

$\begin{array}{llll}\text { E12.5 } & \text { E13.5 } & \text { E15.5 } & \text { E17.5 }\end{array}$

KIMU GARAI GARAI KIMU TERMINAL

GARAIA SASIGURUINDARRA KANALIKULARRA GARAIA

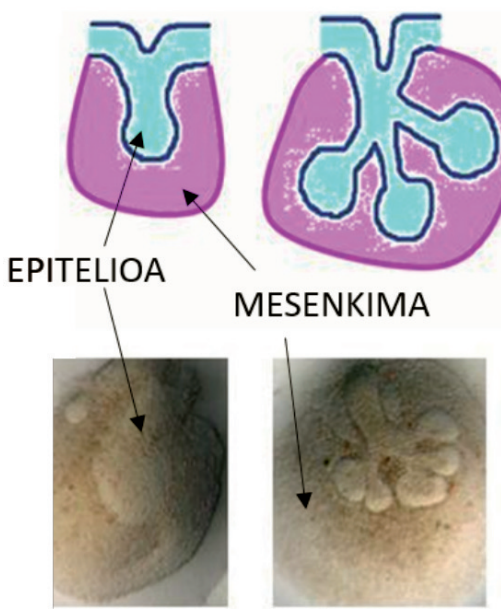

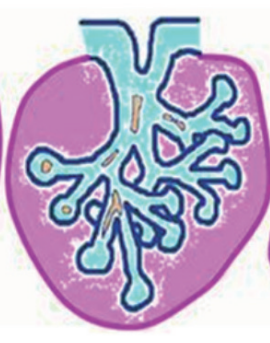

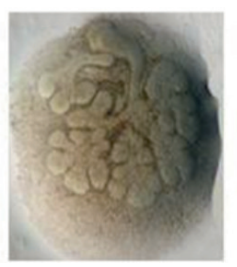

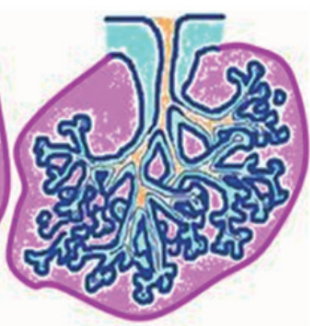

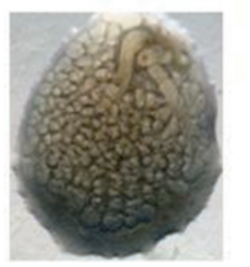

3. irudia. SMGren garapen-garaiak. Listu-guruinaren morfogenesiak epitelio-mesenkima arteko zelulen elkarrekintzak behar ditu. Hasieran, epitelioa mesenkimarantz barneratzen da, eta hasierako kimua sortzen da. Ondoren, garai sasiguruindarrean, kimu hori adarkatuz doa azinoak azkar ugarituz. Aldi berean, epitelioa polarizatzen hasten da, hodien argia sortuz garai kanalikularrean. Azkenik, garai terminalean, zelula epitelialak desberdintzen hasiko dira, eta hodiak sortuko dira.

Sagu-SMGren garapenaren hasiera (3. irudia) mihi-alboko epitelioaren loditze gisa ikusten da, enbrioiaren garapeneko 11,5 (E11,5) egunean. Gero, E12,5 egunean epitelioa inbaginatu egiten da, eta kimu-epitelioa sortzen da, zeina hodi nagusi primitibo baten bidez aho-azalari lotuta da- 
goen. Garai sasiguruindarrean, E13,5ean, epitelioa adarkatuz doa gutxi gorabehera 3-5 kimu sortuz PSGaren axoiez inguratuta. Garapenean dauden hiru-bost kimu horiek saguaren listu-guruin helduaren lobuluei dagozkie. E15,5ean, hodi gehienetan, zeinak zelula multzo batez osatuta dauden, barruko argiak sortzen hasten dira zelulen polarizazioa dela eta. Garai horri kanalikularra deritzo. 17,5 eguneko listu-guruinen adarkaduretan, hodi iraizleen argiak azalduz doaz, eta kimuak azino-jariatzaile bihurtzen dira. Azkeneko garai horri kimu terminala deitzen zaio.

Karraskarien listu-guruinaren garapenak jaio ondoren jarraitzen du, eta azinoen eta jariapen-hodien arteko desberdintzapena heldutasun sexualean gertatzen da $[1,19]$.

\section{LISTU-GURUINAREN GARAPENEKO SEINALIZAZIO-BIDEAK}

Gaur egun, listu-guruina langai garrantzitsua da ehun-ingeniaritzako ikerkuntzan [20, 21]. Organoen morfogenesiaren eta birsorkuntzaren arteko antzekotasunak kontuan hartuz, merezi du listu-guruinaren birsorkuntzarako garapena gidatzen duten seinale molekularrek duten potentziala aztertzea.

Seinalizazio-sarearen interakzio konplexuak ulertzeko lehenik eta behin seinalizazio-bideak banaka aztertu behar dira, horien artean SMGren garapenerako garrantzitsuak eta beharrezkoak direnak zehaztuz. Knock-out saguak, transgenikoak, mutanteak, siRNA-transfekzioa, funtzioa blokeatzeko antigorputzak eta antzeko teknikek, SMGren garapenean parte hartzen duten eta morfogenesirako ezinbestekoak diren seinalizazio-bideen ezagutza zabaldu dute.

Seinalizazio-bideen artean, fibroblastoen hazkuntza-faktoreak (Fibroblast Growth Factor-FGF) barneratzen dituen seinalizazioa bide ikertuenetakoa da, eta ezinbestekoa. FGF familiak 23 kide ditu, bakoitzak bere funtzioa betetzen duela, besteak beste, zelulen proliferazioa, epitelioaren adarkatzea eta ehun-desberdintzapena [22]. Ligandoa hartzailearekin lotzen denean, hartzailearen dimerizazioa gertatzen da. Ondorioz, hartzaileen barneko tirosina-kinasaren jarduera aktibatzen da autofosforilazioz. Ondoren, zelula barneko eragile molekularren aktibitatea pizten da, adibidez, Ras bidea, Src tirosina-kinasen familia, PI3K/AKT, PLC- $\gamma /$ PKC eta STAT3 bidea. Zelulen premien arabera FGF bideak efektu pleiotropikoa du. SMGren morfogenesian, Fgfr2-IIIB(-/-), FgflO(-/-) saguek eta $F g f 8$ baldintzazko knock-out saguek SMGren aplasia dute, zeinak listu-guruinetan FGF bidearen garrantzia erakusten baitu [23].

Sonic Hedgehog (Shh) beste seinalizazio-bide garrantzitsu bat da. Seinalizazio-bidearen molekulak zelulen biziraupenean, proliferazioan, 
Listu-guruinaren enbriogenesia eta seinalizazio-bideak

desberdintzapenean eta enbrioi-patroien sorreran parte hartzen du [24]. Hh ligandoarekiko zelularen erantzuna bi mintz-zeharreko proteinak kontrolatzen dute, Patched (Ptc) eta Smoothened (Smo) izenekoek, zeinak Hhren erregulatzaile positiboa eta negatiboa baitira, hurrenez hurren. Hh Ptc-ri lotzean Smo askatzen da, G proteina bat, zelula barneko molekulen aktibazio kateatua sortzen duena. Aktibazioak gene espezifiko batzuk erregulatzen ditu Gli familiako transkripzio-faktoreen aktibazioaren bitartez. Ptc eta Smo SMGren epitelioan kokaturik egoteak iradokitzen du Shh seinalizazioak proliferazioan eta desberdintzapenean eragina duela modu justakrino batean. Gainera Hh-ren ex vivo aktibazioak eragin positiboa du SMGren adarkatze morfogenesian, eta kalteturik gertatzen da $\mathrm{Hh}$ in vivo eta ex vivo inhibitzen bada [11]. Sagu Shh -/- SMG-k garapeneko atzerapena aurkezten du.

Notch seinalizazio-bidearen funtzio nagusia zelulen zoria kontrolatzea dela iradoki da. Notch bitartez egindako zelulen arteko komunikazioa aldameneko zelulen hartzaile eta ligandoen arteko adierazpenen arabera gertatzen da. Horrela, oreka lortzean zelula-leinu espezifiko bat aukeratuko da [25]. Notch seinalizazio-bide kanonikoa hartzaileen eta ligandoen arteko loturarekin hasten da; ondoren, zatiketa proteolitiko bat gertatzen da. Zelula barneko azpiunitatea libre geratzen da mintz zeharreko eta zelula barneko (NICD) zatiekin. Behin nukleoan dagoela, transkripzio-faktoreei esker itu-geneen adierazpena eragiten da. Notch seinalizazio-bidea ezinbestekoa da barailako listu-guruinaren garapenerako; izan ere, DLK1, Notch seinalizazio-bidearen ligando inhibitzaile bat, listu-guruinekin kontaktuan jartzean horren hazkuntzari eta garapenari ez ezik guruinaren inerbazioari ere kalte egiten dio [26].

Wnt seinalizazio-bidea ez-aktibo dagoenean, $\beta$-katenina proteina zitoplasman kokatzen da, eta APCrekin eta GSK3 $\beta$-rekin batera degradaziokonplexua osatzen du [27]. Aktibatzen denean, aldiz, degradazio-konplexuaren etena gertatzen da, eta $\beta$-katenina askea nukleora traslokatzen da eta itu-geneen adierazpena aktibatzen du. Wnt bide kanonikoa listu-guruinaren garapenarekin eta birsorkuntzarekin erlazionatu da [28]. Listu-guruinaren mesenkiman asko adierazten da seinalizazio-bide hau. Gainera, Wnt seinalizazioa mesenkiman isilarazten bada, adarkatze morfogenesia konprometituta gelditzen da [29]. GSK3 $\beta$-ren immunolokalizazioa eta inhibitzailea erabiliz, GSK3 $\beta$ guruinaren garapenerako adarkatze morfogenesiaren erregulatzaile gisa identifikatu da [30].

Ektodisplasina (Eda) listu-guruinaren morfogenesirako ezinbestekoa dela ikusi da. Saguetan zein gizakietan Eda genearen mutazioak ektodermo-jatorriko ehunen gabeziarekin edota hipoplasiarekin erlazionaturik daude, guruin exokrino guztietan, listu-guruinak barne [17]. Eda eta beraren mintz-hartzailea (Edar) TNF superfamiliako kideak dira. TNF superfamilia garrantzitsua da mitogenesiaren eta apoptosiaren arteko oreka man- 
tentzeko. Edardl (downless) sagu mutanteak listu-guruinaren displasia du. Gainera, listu-guruinaren garapenean Eda seinalizazio-bidea Wnt bidearen azpitik dago eta Hh bidearen gainetik [29].

Seinalizazio-bideez gain, zelulaz kanpoko matrizeak (ECMk) funtzio garrantzitsua du listu-guruinaren garapenean. Adibidez, laminina-111 (4B irudia) eta beraren hartzaile $\alpha 6 \beta 1$ integrina ezinbestekoak dira ex vivo hazitako listu-guruinaren garapenean [31,32]. Integrina $\alpha 3$ genearen mutazioak punta-zelulen polarizazioan akatsak sortzen ditu, eta beraren galerak laminina $\alpha$-rako knock-out saguek duten fenotipo antzerakoa sortzen du. Zelulen mugikortasuna eta kimu epitelioaren ertzetako zelula-matrize elkarrekintzek adarkatze morfogenesiko prozesu ezberdinetan parte hartzen dute. Gainera, metaloproteinasak (MMP) ECMn eragindako eraldaketen ondorioz, produktu bioaktiboak sortzen dira, eta zelulen kanpoko mintz basalean dauden hazkuntza-faktoreen askapenarekin erlazionaturik daude [33]. Hala ere, MMPetarako knock-out sagu gehienek fenotipo ahulak dituzte konpentsazioengatik edo gainezarpen-funtzioengatik.

Beste alde batetik, listu-guruinak oso inerbaturik daude, nerbio-sistema sinpatikoaz zein parasinpatikoaz. Nerbio parasinpatikoek (4. irudia) azetilkolina askatzen dute, eta hala epitelioan dauden hartzaile muskarinikoak aktibatzen dituzte. Ondorioz, jariakinen askapena eragiten dute. Nerbio sinpatikoek listu-jariapena kontrolatzen dute $\alpha$ eta $\beta$ adrenohartzaileen bidez, listu urtsua edo likatsua estimulatuz, hurrenez hurren.
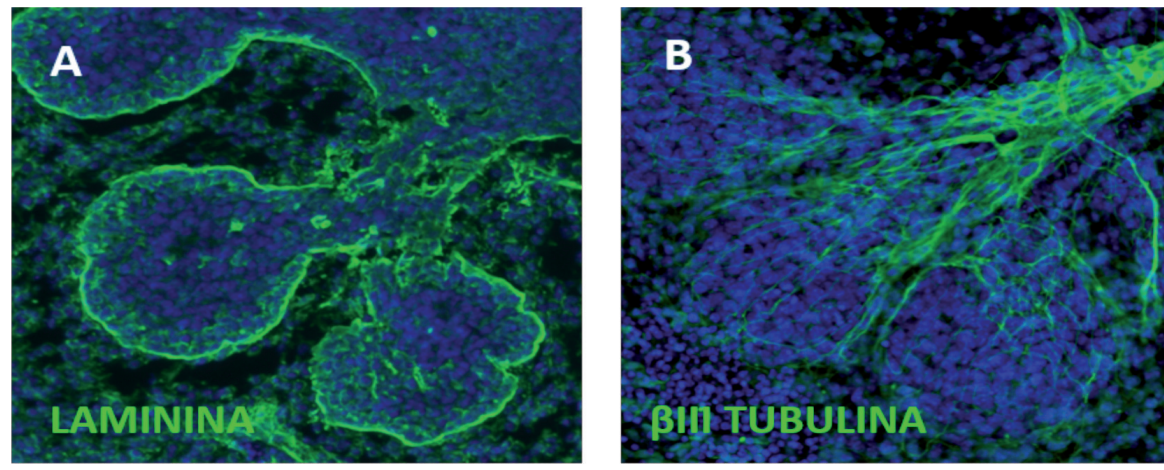

4. irudia. Inerbazio parasinpatikoa eta ECMko laminina. Listu-guruinaren zelula epitelialak eta mesenkimalak (urdinez) (A) inerbazio parasinpatikoaren markaketa $\beta$ III tubulinarekin (berdez). (B) Laminina (berdez) ECMko osagaia epitelioaren kimuak inguratzen. Lamininak eta PSGren axoiek SMGren garapenean parte hartzen dute.

Azkeneko ikerkuntzek SMGren garapenean inerbazioek duten funtzioa aztertu dute batik bat. Gongoil parasinpatikoa (PSG) kentzeak epitelioko 
Listu-guruinaren enbriogenesia eta seinalizazio-bideak

zelula aitzindarietan keratina 5 (CK5) markatzailearen murrizketa eragiten duela egiaztatu da [34]. Gainera, listu-guruinen garapenean PSGren inerbazioak hodien sorkuntza edo tubulogenesiaren sorrera erregulatzen dituela iradoki da [18].

\section{ONDORIOAK}

Listu-guruinaren garapenak, seinalizazio-bideen aktibazioaz gain, zelula ugariren arteko elkarrekintza dakar, besteak beste, zelula epitelial, mesenkimal, endotelial eta neuronalen artekoa. Berrikuspen honek agerian uzten du garapenaz ikasitakoa birsorkuntza-terapiarako erabilgarria dela. Hala ere, ikertzeko asko dago oraindik. Adibidez, garapenaren seinalizazio-bideek zelula mota bakoitzean duten rola argitu behar da. Esperimentu gehiago beharrezkoak dira listu-guruinen jatorria (ektodermikoa ala mesodermikoa) ebazteko. Leinu-erlazioen eta listu-guruineko zelula amen desberdintzapena erregulatzen duten mekanismoa gutxi ezagutzen da. Etorkizunean sakonagoa izango da ezagutza, zehazki zelula mota bakoitzaren biologia eta genetika. Ondorioz, listu-guruinak birsortzeko edota edozein kalte konpontzeko balio izango du, zalantzarik gabe, eta bioingeniaritzarako aurrerapauso garrantzitsua izango da.

\section{BIBLIOGRAFIA}

[1] TUCKER, A.S. 2007. Salivary gland development. Seminars in cell \& developmental biology, 18(2), 237-244.

[2] OSAMU A., KENICHI M., YASUHIKO B., KOJI S. 2012. «Anatomy and histology of rodent and human major salivary glands.» 45(5),. 241-250.

[3] HOSOI, K., KOBAYASHI, S. and UEHA, T. 1978. «Sex difference in 1glutamine d-fructose-6-phosphate aminotransferase activity of mouse submandibular gland.» Biochimica et biophysica acta, 543(3), 283-292.

[4] BOUMA, I., PIJPE, J. and VISSINK, A. 2003. «Sjogren' syndrome: a progressive disease.» Nederlands tijdschrift voor tandheelkunde, 110(8), 316-320.

[5] VISSINK, A., KALLENBERG, C.G. and BOOTSMA, H. 2010. «Treatment approaches in primary sjogren syndrome.» Jama, 304(18), 2015-6; author reply 2016.

[6] LOMBAERT, I.M., BRUNSTING, J.F., WIERENGA, P.K., FABER, H., STOKMAN, M.A., KOK, T., VISSER, W.H., KAMPINGA, H.H., DE HAAN, G. and COPPES, R.P. 2008. «Rescue of salivary gland function after stem cell transplantation in irradiated glands.» Plos one, 3(4), E2063.

[7] KNOX, S.M., LOMBAERT, I.M., HADDOX, C.L., ABRAMS, S.R., COTRIM, A., WILSON, A.J. and HOFFMAN, M.P. 2013. «Parasympathetic stimulation improves epithelial organ regeneration.» Nature communications, 4, 1494. 
[8] REBUSTINI, I.T. and HOFFMAN, M.P. 2009. «Ecm and fgf-dependent assay of embryonic smg epithelial morphogenesis: investigating growth factor/ matrix regulation of gene expression during submandibular gland development.» Methods in molecular biology (clifton, n.j.), 522, 319-330.

[9] DANG, H., LIN, A.L., ZHANG, B ., ZHANG, H.M., KATZ, M.S. and YEH, C.K. 2009. «Role for notch signaling in salivary acinar cell growth and differentiation.» Developmental dynamics : an official publication of the american association of anatomists, 238(3), 724-731.

[10] JASKOLL, T., WITCHER, D., TORENO, L., BRINGAS, P., MOON, A.M. and MELNICK, M. 2004a.»Fgf8 dose-dependent regulation of embryonic submandibular salivary gland morphogenesis.» Developmental biology, 268(2), 457-469.

[11] JASKOLL, T., LEO, T., WITCHER, D., ORMESTAD, M., ASTORGA, J., BRINGAS, P., JR, CARLSSON, P. AND MELNICK, M. 2004b. «Sonic hedgehog signaling plays an essential role during embryonic salivary gland epithelial branching morphogenesis.» Developmental dynamics : an official publication of the american association of anatomists, 229(4), 722-732.

[12] PATEL, N., SHARPE, P.T. AND MILETICH, I. 2011. "Coordination of epithelial branching and salivary gland lumen formation by wnt and fgf signals.» Developmental biology, 358(1), 156-167.

[13] DUDEK, R. AND FIX, J. 1998. Embryology. Baltimore: Williams and Wilkins.

[14] AVERY, J. 2002. Oral development and histology. New york: thieme.

[15] HISATOMI, Y., OKUMURA, K., NAKAMURA, K., MATSUMOTO, S., SATOH, A., NAGANO, K., YAMAMOTO, T. and ENDO, F. 2004. «Flow cytometric isolation of endodermal progenitors from mouse salivary gland differentiate into hepatic and pancreatic lineages.» Hepatology (baltimore, $m d.), 39(3), 667-675$.

[16] JASKOLL, T., ZHOU, Y.M., CHAI, Y., MAKARENKOVA, H.P., COLLINSON, J.M., WEST, J.D., HAJIHOSSEINI, M.K., LEE, J. and MELNICK, M. 2002. «Embryonic submandibular gland morphogenesis: stage-specific protein localization of fgfs, bmps, pax6 and pax9 in normal mice and abnormal smg phenotypes in fgfr2-iiic(+/delta), bmp7(-/-) and pax6(-/-) mice.»Cells, tissues, organs, 170(2-3), 83-98.

[17] JASKOLL, T., ZHOU, Y.M., TRUMP, G. and MELNICK, M. 2003. «Ectodysplasin receptor-mediated signaling is essential for embryonic submandibular salivary gland development.» The anatomical record.part a, discoveries in molecular, cellular, and evolutionary biology, 271(2), 322-331.

[18] PATEL, V.N. and HOFFMAN, M.P. 2014. «Salivary gland development: a template for regeneration.» Seminars in cell \& developmental biology, 25-26, 52-60.

[19] GRESIK, E.W. 1994. «The granular convoluted tubule (gct) cell of rodent submandibular glands.» Microscopy research and technique, 27(1), 1-24. 
Listu-guruinaren enbriogenesia eta seinalizazio-bideak

[20] OGAWA, M., OSHIMA, M., IMAMURA, A., SEKINE, Y., ISHIDA, K., YAMASHITA, K., NAKAJIMA, K., HIRAYAMA, M., TACHIKAWA, T. and TSUJI, T. 2013. «Functional salivary gland regeneration by transplantation of a bioengineered organ germ.» Nature communications, 4, 2498.

[21] LIU, F. and WANG, S. 2014. «Molecular cues for development and regeneration of salivary glands.» Histology and histopathology, 29(3), 305-312.

[22] SZEBENYI, G. and FALLON, J.F. 1999. «Fibroblast growth factors as multifunctional signaling factors.» International review of cytology, 185, 45106.

[23] MELNICK, M. and JASKOLL, T. 2000. «Mouse submandibular gland morphogenesis: a paradigm for embryonic signal processing.» Critical reviews in oral biology and medicine: an official publication of the american association of oral biologists, 11(2), 199-215.

[24] MCMAHON, A.P., INGHAM, P.W . and TABIN, C.J. 2003. «Developmental roles and clinical significance of hedgehog signaling.» Current topics in developmental biology, 53, 1-114.

[25] ARTAVANIS-TSAKONAS, S., RAND, MD. and LAKE, R.J. 1999. «Notch signaling: cell fate control and signal integration in development.» Science, 284(5415), 770-776.

[26] GARCIA-GALLASTEGUI, P., IBARRETXE, G., GARCIA-RAMIREZ, J.J., BALADRON, V., AURREKOETXEA, M., NUEDA, M.L., NARANJO, A.I., SANTAOLALLA, F., SANCHEZ-DEL REY, A., LABORDA, J. and UNDA, F. 2014. «Dlk1 regulates branching morphogenesis and parasympathetic innervation of salivary glands through inhibition of notch signalling.» Biology of the cell / under the auspices of the european cell biology organization, 106(8), 237-253.

[27] WU, G., XU, G., SCHULMAN, B.A., JEFFREY, P.D., HARPER, J.W. and PAVLETICH, N.P. 2003. «Structure of a beta-trcp1-skp1-beta-catenin complex: destruction motif binding and lysine specificity of the scf(beta-trcp1) ubiquitin ligase.» Molecular cell, 11(6), 1445-1456.

[28] HAI, B., YANG, Z., MILLAR, S.E., CHOI, Y.S., TAKETO, M.M., NAGY, A. and LIU, F. 2010. «Wnt/beta-catenin signaling regulates postnatal development and regeneration of the salivary gland.» Stem cells and development, 19(11), 1793-1801.

[29] HaARA, O., FUJIMORI, S., SCHMIDT-ULLRICH, R., HARTMANN, C., THESLEFF, I. and MIKKOLA, M.L. 2011. «Ectodysplasin and wnt pathways are required for salivary gland branching morphogenesis.» Development (cambridge, england), 138(13), 2681-2691.

[30] MUSSELMANN, K., GREEN, J.A., SONE, K., HSU, J.C., BOTHWELL, I.R., JOHNSON, S.A., HARUNAGA, J.S., WEI, Z. and YAMADA, K.M. 2011. «Salivary gland gene expression atlas identifies a new regulator of branching morphogenesis.» Journal of dental research, 90(9), 1078-1084

[31] KADOYA, Y., KADOYA, K., DURBEEJ, M., HOLMVALL, K., SOROKIN, L. and EKBLOM, P. 1995. «Antibodies against domain e3 of lam- 
inin-1 and integrin alpha 6 subunit perturb branching epithelial morphogenesis of submandibular gland, but by different modes.» The journal of cell biology, 129(2), 521-534.

[32] KADOYA, Y., NOMIZU, M., SOROKIN, L.M., YAMASHINA, S. and YAMADA, Y.. 1998. «Laminin alpha1 chain g domain peptide, rkrlqvqlsirt, inhibits epithelial branching morphogenesis of cultured embryonic mouse submandibular gland.» Developmental dynamics: an official publication of the american association of anatomists, 212(3), 394-402.

[33] CATALAN, M.A., NAKAMOTO, T. and MELVIN, J.E. 2009. «The salivary gland fluid secretion mechanism.» The journal of medical investigation, 56, 192-196.

[34] KNOX, S.M., LOMBAERT, I.M., REED, X., VITALE-CROSS, L., GUTKIND, J.S. and HOFFMAN, M.P. 2010. «Parasympathetic innervation maintains epithelial progenitor cells during salivary organogenesis.»Science, 329(5999), 1645-1647. 